\title{
Deformasyon Tahmininde Gri Model Uygulaması: Keban Barajı Örneği
}

\author{
Erkan TANYILDIZI ${ }^{1}$, Kürşat KAYA ${ }^{2 *}$ \\ ${ }^{1}$ Frrat Üniversitesi, Teknoloji Fakültesi, Yazılım Mühendisliği Bölümü, Elazı̆̆ \\ 2 İnönü Üniversitesi, Malatya Meslek Yüksekokulu, Harita ve Kadastro Bölümü, Malatya \\ *1 etanyildizi@firat.edu.tr, ${ }^{2}$ kursat.kaya@inonu.edu.tr
}

\begin{abstract}
Öz: Büyük mühendislik yapılarının şekil, boyut ve yer değişimleri, farklı deformasyon analiz metotlarıyla belirlenmekte ve yorumlanmaktadır. Deformasyon analizinde kullanılan Gri Sistem, bulanık mantık yaklaşımına alternatif bir yöntem olarak sunulmuştur. $\mathrm{Bu}$ çalışmada Fırat Nehri üzerinde inşa edilmiş olan Keban Barajındaki deformasyon ölçmelerinin belirlenmesinde ve analiz edilmesinde Gri sistem metodunun kullanılabilirliği araştırılmıştır. Keban barajında, jeoteknik ölçü yöntemi kullanılarak deformasyon ölçüleri yapılmış olan ölçü noktalarına ait boşluk suyu basınçları ve baraj göletindeki su seviyesindeki değişimler, gri sistem metoduyla tahmin edilmiştir. Keban Barajı'nda yapılan ölçü değerleriyle hesaplanan deformasyon miktarları, Gri Sistem yöntemiyle elde edilen tahmini deformasyon miktarları ile karşılaştırılmış ve tahmin başarısı elde edilmiștir.
\end{abstract}

Anahtar kelimeler: Deformasyon Analizi, Gri Sistem, Deformasyon Ölçmeleri, Keban Baraj1.

\section{Application of Gray Model in Estimation of Deformation: The Case of Keban Dam}

\begin{abstract}
Shape, size and displacement of big engineering structures are determined and interpreted by different deformation analysis methods. The Gray System used in deformation analysis is presented as an alternative method to the fuzzy logic approach. $\mathrm{n}$ this study, the usability of the Gray System method for the determination and analysis of deformation measurements in the Keban Dam built on the Euphrates River was investigated. In the Keban dam, the pore water pressures and the changes in the water level in the reservoir were estimated by the gray system method. The deformation amounts calculated by the measured values at the Keban Dam were compared with the estimated deformation amounts obtained by the Gray System method and the prediction success was obtained.
\end{abstract}

Key words: Deformation Analysis, Gray System, Deformation Measurements, Keban Dam.

\section{Giriş}

Yüksek bütçe ve fazla emek harcanarak inşa edilen büyük yapıların bakım ve tadilatlarının eksiksiz ve zamanında yapılması önem taşımaktadır. Bu sebepten yapılarda ve çevresinde meydana gelen değişimlerin izlenmesi, belirlenmesi ve tanımlanması önemlidir. Ortaya çıkabilecek olumsuzluklar, yapı çevresindeki canlılar ve doğa için ciddi zararlara neden olabilmektedir. Bu zararların önüne geçebilmek için yapılarda meydana gelen değişimlere sebep olan etmenlerin belirlenmesi gerekir. Bu etmenlerden, önlenebilir olanlar için gerekli tedbirler zamanında alınabilir. Cisimlerde meydana gelen değişimlerin yorumlanmasında, çeşitli analiz yöntemleri kullanılmaktadır. Analiz yönteminin seçimi, değişimi belirlemek için kullanılan gözlemlerin hangi yöntemle yapıldığına bağlıdır. Yeterli çalışmanın yapılmadığı, gerekli verilerin oluşturulamadığı veya oldukça kısıtlı veriye erişilebildiği durumlar söz konusu olabilir. Bu gibi durumlarda memnuniyet verici uygulamalar yapabilme gücünde olan ve deformasyon analizi yapabilme kabiliyetine sahip olan Gri Sistem yaklaşımı ortaya konulmuştur. Gri Sistemde temel düşünce, belirsiz sistemlerin davranışlarını sınırlı sayıda veri yardımı ile tahmin etmektir.

Bu çalışmada büyük bir öneme sahip olan Keban Barajının deformasyon ölçmeleri ve deformasyon analizi farklı bir yaklaşımla irdelenmiştir. Bu çalışmada, birçok kullanım alanına sahip olan gri tahmin yönteminin, deformasyon analizinde kullanılabilirliği Matlab ortamında hazırlanan yazılım paketi ile test edilmiştir. Yazılım paketine deformasyon ölçülerine ait veriler girilerek, gelecek dönemlere ait deformasyon ölçüleri tahmin edilmiştir. Bu amaçla, daha önceden periyodik olarak deformasyon ölçüleri yapılmış olan Keban Barajına ait deformasyon verileri referans alınmıştır. Elazığ İli civarında Fırat Nehri üzerine inşa edilmiş olan Keban Barajı, su tutma tarihi olan 1975 yılından bu yana düzenli periyotlarla deformasyon ölçüleri yapılmış olmasından dolayı tercih edilmiştir.

\footnotetext{
* Sorumlu yazar: kursat.kaya @inonu.edu.tr. Yazarların ORCID Numarası: ${ }^{1}$ 0000-0003-2973-9389, ${ }^{2}$ 0000-0002-9647-247X
} 


\section{Deformasyon Ölçme Yöntemleri}

Deformasyon ölçme yöntemleri, kullanılan ölçü aletleri, ölçüm yöntemi ve ölçüm yeri bakımından, Jeoteknik (fiziksel yada mekanik) ölçme yöntemleri ve jeodezik ölçme yöntemleri olarak iki grupta incelenir [1]. Jeoteknik yöntemle yapılan deformasyon ölçülerinde kullanılan ölçü aletleri, yapının temeline, gövdesi içine veya yüzeyine yerleştirilir. Bu ölçü aletleri ile yapı içerisinde yerleştirildiği yerdeki yatay ve düşey hareketler ölçülür. Ölçülen hareketler, deformasyon ölçüsü yapılan yapıdan uzak bir noktada kontrol edilir [2]. Jeoteknik yöntem ile yapılan ölçümlerde elde edilen sonuçlar, yapının bütününün hareketinden ziyade, yerleștirildiği noktadaki değișimi algılarlar. Bu yöntem ile genelde toplam gerilmeler ile gerilme değişimi, deformasyon, yük ile birim yer değiştirme, 1S1 vb. değerler ölçülür. Jeoteknik yöntemle yapılan ölçülerde kullanılan bazı aletler; piyezometreler, inklinometreler, gerilme ölçerler ve su basınç ölçerlerdir. Jeodezik ölçme yöntemleri, düşey yöndeki deformasyon ve yatay yöndeki deformasyon ölçme yöntemleri olarak ikiye ayrılır. Her iki ölçme yöntemi, kullanılan ölçü aletleri ve ölçüm hassasiyetleri bakımından farklılık gösterirler. Düşey yöndeki deformasyonlar, yapılarda oturma veya çökme şeklinde kendini gösterir. Düşey yönde yapılan bu hareket yapının kendisinden ziyade yapının inşa edildiği zemin ile alakalı bir durumdur. Düşey yöndeki deformasyonlar, hassas düşey açı ölçebilen veya hasssas yükseklik farkı ölçebilen aletler ile belirlenir. Yatay yöndeki deformasyon kayma veya dönme şeklinde görülür. Yatay yöndeki deformasyonların tespiti için bir nirengi ağı oluşturulur. Yatay yöndeki deformasyonlar hassas poligon yöntemi veya aliyman yöntemlerinden biriyle belirlenebilir.

Farklı periyotlarda yapılan ölçüler değerlendirilirken zaman ve büyüklük parametrelerine bağlı olarak, yer değiştirmelerin belirlenmesi ve elde edilen yer değiştirmelerin yorumlanması işlemine deformasyon analizi denir [3]. Deformasyon ölçülerinin yorumlanmasında geçmişten günümüze kadar birçok deformasyon analiz yöntemi kullanılmıştır. Bu analiz yöntemleri, pratikliği, kullanım kolaylığı, ölçü ağının yapısı, ölçme planı vb. sebeplerden dolayı farklılıklar ya da benzerlikler gösterirler.

\subsection{Deformasyon Ölçülerinin Dengelenmesi}

Belirli periyotlarla yapılmış deformasyon ölçülerinin karșılaştırılabilmesi için her periyot kendi içerisinde değerlendirilerek uyuşumsuz ölçülerin belirlenmesi gerekir. Bu yaklaşım, Gauss Markoff Modeline dayandırılır ve bazı test kurallarına göre, daha önceden belirlenmiş kriterler ile çelişen düzeltme değerlerinin belirlenmesi ile yapılır. Belirlenen kaba hatalı ölçüler, ya kümeden çıkarılır, ya yeniden ölçülür yada ağırlığına müdahale edilerek etkisi azaltılır [4].

Kaba hatalı ölçülerin etkisini azaltmak için ölçülerin dengelenmesi gerekir. Dengeleme yapmak için yapılan ölçüler Denklem 1 de verilen kritere tabi tutulur ve dengeleme kararı bu kritere göre verilir.

$f=n-u+d$

burada $n$ : ölçü sayısı, $u$ : bilinmeyen sayısı, $d$ : Datum parametresi (tek boyutlu ölçülerde $d=1$, iki boyutlu ölçülerde $d=2$, üç boyutlu ölçülerde $d=3$ ), $f$ : fazla ölçü dür.

Fazla ölçü sayısına göre;

- $\quad f>0$ veya $n>u$ ise fazla ölçü var $\rightarrow$ Dengeleme yapılmalı

- $f=0$ veya $n=u$ ise yeteri kadar ölçü var $\rightarrow$ Tek anlamlı çözüm

- $f<0$ veya $n<u$ ise yeterli ölçü yok $\rightarrow$ İteratif çözüm [5].

Yapılan çalışmada bilinmeyen sayısı ölçü sayısına eşit olduğu için tek anlamlı çözüm yoluna gidilmiştir.

\subsection{Gri Sistem Yöntemi ile Deformasyon Analizi}

Gri Sistem teorisi ilk olarak 1980'li yılların başında ortaya çıkmıştır. Gri Sistem teorisi, belirsizliğin sayılaştırılmasına alternatif bir metottur. Ortaya çıkışındaki temel düşünce stokastik veya bulanık yöntemlerle üstesinden gelinemeyen belirsiz sistemlerin davranışlarını, sınırlı sayıda veri yardımı ile tahmin etmektir [6]. Sosyal, ekonomik, endüstriyel, tarımsal, biyolojik sistemler gibi pek çok sistem ismini ilgili olduğu alandan alır. Gri Sistem ismi ise, incelenen konuya ait bilgi düzeyi esas alınarak seçilmiştir [7]. Gri Sistem teorisinde, belirsizliğin olmadığı kusursuz bilgiye sahip olan bir sistem beyaz renk ile sembolize edilmiştir. Tam zit özelliklere sahip olan sistem ise siyah olarak nitelendirilmiştir. Yalnızca kısmi bilgiye sahip olunan sistemler ise "Gri Sistemler"' olarak isimlendirilmiştir [8].

Çoğu zaman tam olmayan, eksik bilgi ve varsayımlar altında modeller kurulur ve kararlar verilir. Hayattaki başımıza gelen olayların, karşılaştığımız problemlerin, tasarladığımız veya kendiliğinden gelişen süreçlerin çoğunluğu hiçbir zaman ne tam siyah ne de tam beyazdır. Örneğin inşaat sektöründe tesis edilecek yapı bünyesinde 
yer alan kumun, demirin ve çimentonun kalitesi gibi faktörler tümüyle bilinse bile, doğa koşulları, işçilik kalitesi gibi pek çok belirsizlik nedeniyle yapının sağlamlığını ve ömrünü tam olarak belirlemek mümkün değildir. Gri Sistem teorisinin ortaya çıkış felsefesi de bu fikirlere dayanmaktadır.

\subsection{Gri Sistemle Deformasyon Tahmini}

Gri tahmin yöntemi, sistem davranışları hakkında yeterli veriye sahip olmadığımız durumlarda, kabul edilebilir sonuçların üretildiği bir yöntemdir. Uygulama kısmında ise yukarıda bahsedilen gri model çeşitlerinden en çok kullanılan $\mathrm{GM}(1,1)$ ve $\mathrm{GM}(1, \mathrm{~N})$ tahmin modellerini, Keban Barajı'ndaki jeoteknik (fiziksel) deformasyon ölçü yöntemi ile yapılan deformasyon ölçülerinin analizinde kullanılmıştır.

\section{a) $\operatorname{GM}(1,1)$ Tahmin Modeli}

Gri Sistem belirsizliğin ve veri yetersizliğinin olduğu durumlarda, durumsal analiz, karar verme ve tahmin yapabilme yeteneğine sahip bir sistemdir. Söz konusu sistemin tek değişkenli ve türevlenebilir modellemesi olan GM(1,1) tahmin modeli doğrusal davranış gösteren bir sistemdir. Referans alınan verilerin davranışlarına göre doğrusal artan veya doğrusal azalan bir grafik oluşturur. GM $(1,1)$ tahmin modelininin matematiksel ifade şekli birçok kaynakta ayrıntılı olarak açıklanmıştır [1].

\section{b) $\mathbf{G M}(1, \mathbf{N})$ Tahmin Modeli}

N adet degişkene sahip birinci dereceden türevlenebilir eşitliklerin yer aldığı model türüdür. Genellikle dinamik faktör analizi amaçlı kullanılır. Farklı değişkenlerin davranışlarına göre tahmin değerleri elde edilir. Değişkenlerin ortak davranışları tahmin değerlerinin şekillenmesinde oldukça etkilidir. Bu model türü (N-1) adet bağımsız değiş̧ken ve bir bağımlı değişken içerir. Çok değişkenli (Multi-Variable Grey Model) modelde denir ve MGM $(n, m)$ şeklinde ifade edilir. Burada, $n$ diferansiyel denklem sırasını ve $m$ ise denklem içerisindeki değişken sayısını gösterir. MGM $(1, \mathrm{~N})$ model, birikimli üretim operatörü (Accumulating Geneation Operator (AGO)) ile kurulur. Başlangıç verileri, AGO ile raslantısal ve değişken özellikte verilere dönüştürülür. Başlangıç verisi, eşit zaman aralıklı ve negatif olmayan ardışık veri serilerini kapsar [1].

\section{Uygulama}

Çalışmamızda, Keban Barajında jeoteknik ölçü aletleriyle tespit edilen boşluk suyu basınç miktarı ve baraj göledindeki su kotunun, 2010 yılından 2015 yıllarına kadar olan ölçü değerleri kullanılmıştır. Gri modelin tek değişkenli tahmin modeli GM $(1,1)$ ve çok değişkenli tahmin modeli $\mathrm{GM}(1, \mathrm{~N})$ kullanılarak baraj kretindeki boşluk suyu basınç değerleri ile baraj gölündeki su miktarı 2023 yılına kadar tahmin edilmiştir. Tahmin değerleri elde edilirken 2010-2015 yılları arasındaki ölçülen değerler, referans verisi olarak kullanılmıştır. Böylece Gri sistemin deformasyon tahminindeki kullanılabilirliği test edilmiştir.

\section{1. Çalıșma alanı}

Keban Barajı, Elazığ'in 45 km kuzeybatısında, Malatya'nın 65 km kuzeydoğusunda olup, Karasu ve Murat Nehirlerinin birleştiği yerden $10 \mathrm{~km}$ daha aşağıda nehrin aktığı en dar boğazlarından birindedir (Şekil 1). Karasu ile Murat Nehirlerinin birleşmeleri ile meydana gelen Fırat Nehri'nin bu birleşme noktasından itibaren ilk uygun baraj yeridir [9]. Barajın su tutmaya başladığı tarihten itibaren jeodezik ve jeoteknik (fiziksel) yöntemlerle sızıntı ve kaçak su miktarının tespit edilmesi için deformasyon ölçümleri ve analizleri DSİ personelince kayıt altına alınmıştır. DSİ arşivlerinden yararlanılarak elde edilen ölçüm değerleri referans verisi olarak kullanılmıştır. Keban Barajı'nın 2010 yılından 2015 yıllarına kadar geçen süre içerisinde değișen su seviyesini ve kil dolgu kısmında yer alan piyezometrelerin tespit ettiği boşluk suyu basınç değerleri, çalışmamızda ölçülen değer olarak alınmıştır.

Barajın kil dolgu kısmındaki piyezometrelerin okuduğu boşluk suyu basınç değerleri Gri Sistemin çok değişkenli $\operatorname{GM}(1, \mathrm{~N})$ model türüyle tahmin edilmiştir. Tahmin değerleri elde edilirken değişken olarak piyezometrelerin rakamsal isimleri (P5, P13 ve P19) ile su kotu değerleri kullanılmıştır. Piyezometreler tercih edilirken baraj kretine yerleştirildikleri piyezometre uç kotlar dikkate alınmıştır. Uç kotu en düşük olan 19 numaralı piyezometre (P19) baraj kretinin 720.00 metresinde yer alırken, kotu en büyük olan yani yüzeye en yakın kotta bulunan 13 numaralı (P13) piyezometrenin uç kotu 810.00 metredir. 5 numaralı piyezometrenin uç kotu ise (P5) baraj kretinin 730.00 metresinde yer almaktadır. Baraj kreti üzerinde onlarca piyezometre bulunduğu halde, 
seçilen piyezometreler baraj kretinin en alt, en yüksek ve orta kısmında yer alan ve düzenli olarak ölçümleri kayıt altına alınmış değerlere sahip olan piyezometreler arasında seçilmiştir.

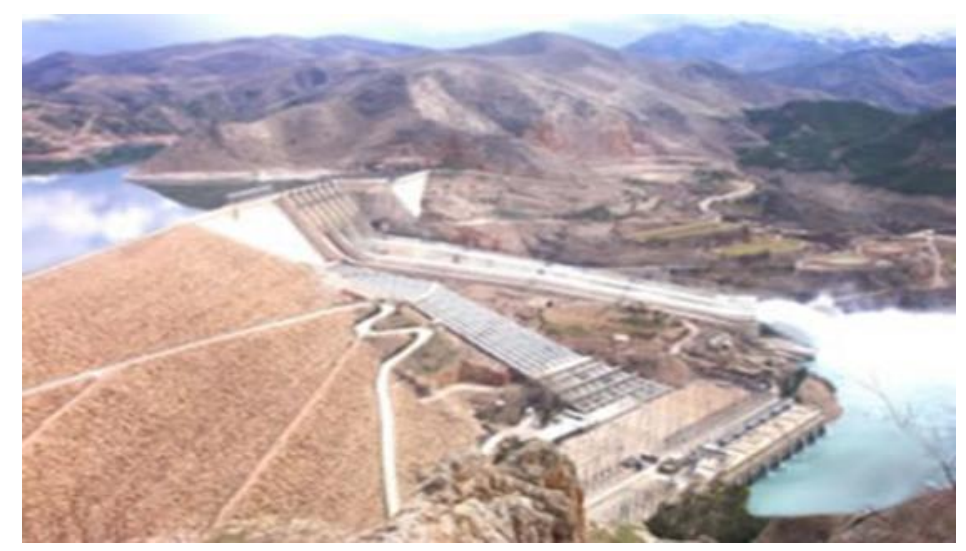

Şekil 1. Keban Baraj1 [10].

\section{Bulgular ve Tartışma}

Seçilen piyezometrelere ait ölçüm değerleri, tahmin değerlerini elde etmek için kullanılmıştır. Gri Sistem ile tahmin değerlerini hesaplayabilmek için tahmin modellerinin matematiksel ifade şekli, Matlab ortamında hazırlanan bir yazılım oluşturulmuştur. Bu yazılım paketine, ".dat" dosyası olarak hazırlanmış referans verilerini, giriş verisi olarak kullanmıştır. Giriş verisinde Keban Barajı'na ait piyezometre ölçüm aletlerinin okuduğu boşluk suyu basınç değerler ile su miktarının, 2010 yılından itibaren ölçülen ilk altı ölçüm değeri yer almaktadır. Bu verilerin değişim miktarların kullanarak piyezometrelerin okuduğu boşluk suyu basınç değerlerini ve su kotu değerleri Gri sistem yöntemi ile tahmin etmiştir. Tahmin edilen değerler ile deformasyon yorumu yapılmıştır. Deformasyon varlığından söz edebilmek için piyezometrelerin okuduğu boşluk suyu basınç değerlerinin yerçekimi katsayısına $\left(9,81 \mathrm{gr} / \mathrm{cm}^{2}\right)$ bölünmesiyle elde edilen değerden yararlanılmıştır. Piyezometrenin hücre kotuna, tahmin edilen boşluk suyu değerinin eklenmesiyle bulunan sonuç, membaa tarafinda yer alan su kotu değerinden büyük olması durumunda deformasyonun olduğunun göstergesidir.

Gri Sistem modelinin tek değişkenli tahmin modeli olan GM(1,1) yöntemiyle yapılan Keban Barajı'ndaki su kotu seviyesine ait tahmin değerleri ve ölçülen değerler Tablo 1'de yer almaktadır.

Tablo 1. Su kotuna ait ölçü ve tahmin değerleri.

\begin{tabular}{|c|c|c|}
\hline \multirow{2}{*}{ Ylllar } & \multicolumn{2}{|c|}{ Su Kotu } \\
\cline { 2 - 3 } & Ölçülen Değer (metre) & GM(1,1) \\
\hline 2010 & $\mathbf{8 3 4 . 1 1 0}$ & 834.110 \\
\hline 2011 & $\mathbf{8 4 0 . 1 0 0}$ & 839.848 \\
\hline 2012 & $\mathbf{8 3 7 . 2 7 0}$ & 837.918 \\
\hline 2013 & $\mathbf{8 3 8 . 4 4 0}$ & 835.993 \\
\hline 2014 & $\mathbf{8 3 0 . 1 1 0}$ & 834.072 \\
\hline 2015 & $\mathbf{8 3 4 . 0 7 0}$ & 832.156 \\
\hline 2016 & 840.360 & 830.244 \\
\hline 2017 & 834.700 & 828.337 \\
\hline 2018 & 833.524 & 826.434 \\
\hline 2019 & Tahmin Değeri & 824.535 \\
\hline 2020 & Tahmin Değeri & 822.641 \\
\hline 2021 & Tahmin Değeri & 820.751 \\
\hline 2022 & Tahmin Değeri & 818.865 \\
\hline 2023 & Tahmin Değeri & 816.983 \\
\hline
\end{tabular}


Tablo 1'de yer alan değerlerden koyu renk ile ifade edilenler, ölçülen değerlerdir. Tahmin değerleri ise gri model kullanılarak elde edilen değerlerdir. Elde edilen değerler gelecek yıllara ait deformasyon tahmininde kullanılmaktadır. GM(1,1) tahmin değerleri, ilk tahmin değerinden sonra doğrusal olarak azalmıştır. Ancak ölçülen gerçek su kotu seviyesi, yağış rejimine bağlı olarak 2011, 2013, 2015 yıllarında artmış, 2012, 2014 yıllarında azalma göstermiştir. Tablo 1'de yer alan 2016 yılına ait su kotu tahmin değeri $830.244 \mathrm{~m}$ iken, DSİ personelince ölçülen değer 840.360 metredir. Aynı şekilde 2017 yılı için tahmin edilen değer $828.337 \mathrm{~m}$ iken, ölçülen değer 834.700 metredir. Benzer şekilde 2018 y1lı için tahmin edilen değer $826.434 \mathrm{~m}$, barajda ölçülen su kotu değeri 833.524 metredir. Yağış miktarındaki ve dolayısıyla su kotu seviyesindeki değişim miktarı, tahmin değerlerini gösteren $\operatorname{GM}(1,1)$ eğrisinde anlamlı olarak temsil edilememiştir. Bu durum $\operatorname{GM}(1,1)$ tahmin modelinin referans değerlerinin artan veya azalan durumlarına göre doğrusal olarak tahmin değeri üretmesinden kaynaklandığı düşünülmektedir.

Tablo 2' de yer alan 5 numaralı piyezometreye ait ölçülen boşluk suyu basınç değerleri ile gri modelin tek değişkenli $\mathrm{GM}(1,1)$ ve çok değişkenli tahmin modeli $\mathrm{GM}(1, \mathrm{~N})$ ile elde edilen tahmin değerleri yer almaktadır. Tablo 2' de ölçülen değer sütununda yer alan altı değer referans verisi olarak kullanılmıştır. 2016 yılından 2023 yılına kadar olan değerler ise tahmin edilmiştir. Gri modelin her iki tahmin modeli ile referans verisi olarak kullanılan değerler yardımıyla sonraki yıllara ait boşluk suyu basınç değerleri tahmin edilmiştir. Tablo 2'de verilen hata oranları incelendiğinde $\operatorname{GM}(1,1)$ tahmin değerlerinin hata oranlarının diğer tahmin değerlerine göre fazla çıtı̆̆ı görülmüştür.

Tablo 2. 5 Nolu piyezometre aletine ait tahmin değerleri.

\begin{tabular}{|c|c|c|c|c|c|}
\hline \multirow[b]{2}{*}{ Yillar } & \multicolumn{5}{|c|}{ P5 Nolu Piyezometre } \\
\hline & $\begin{array}{l}\text { Ölçülen Değer } \\
\left(\mathbf{k g} / \mathrm{cm}^{2}\right)\end{array}$ & $\begin{array}{l}\text { GM(1,1) } \\
\text { (P5) }\end{array}$ & $\begin{array}{l}\text { GM(1,2) } \\
(\text { P5-P13) }\end{array}$ & $\begin{array}{c}\text { GM(1,3) } \\
\text { (P5-P13-P19) }\end{array}$ & $\begin{array}{c}\text { GM(1,4) } \\
\text { (P5-P13-P19-Su Kotu) }\end{array}$ \\
\hline 2010 & 1350 & 1350.000 & 1350.000 & 1350.000 & 1350.000 \\
\hline 2011 & 230 & 301.606 & 246.289 & 248.487 & 253.775 \\
\hline 2012 & 390 & 332.265 & 369.401 & 373.391 & 357.817 \\
\hline 2013 & 395 & 366.041 & 410.356 & 400.381 & 427.264 \\
\hline 2014 & 420 & 403.251 & 415.169 & 409.198 & 381.030 \\
\hline 2015 & 410 & 444.243 & 404.489 & 414.209 & 417.702 \\
\hline 2016 & Tahmin Değeri & 489.402 & 387.557 & 418.042 & 421.061 \\
\hline 2017 & Tahmin Değeri & 539.152 & 368.489 & 421.213 & 351.452 \\
\hline 2018 & Tahmin Değeri & 593.958 & 349.099 & 423.853 & 509.127 \\
\hline 2019 & Tahmin Değeri & 654.337 & 330.167 & 426.024 & 262.437 \\
\hline 2020 & Tahmin Değeri & 720.852 & 312.008 & 427.769 & 565.395 \\
\hline 2021 & Tahmin Değeri & 794.130 & 294.736 & 429.126 & 287.041 \\
\hline 2022 & Tahmin Değeri & 874.856 & 278.368 & 430.131 & 411.439 \\
\hline 2023 & Tahmin Değeri & 963.789 & 262.887 & 430.814 & 605.305 \\
\hline \multicolumn{2}{|c|}{ Hata Oranı } & 2.227 & 0.532 & 0.599 & 0.475 \\
\hline
\end{tabular}

5 Nolu piyezometreye ait tahmin değerlerine bağlı olarak deformasyon durumu Tablo 3 'te verilmiştir. Tablo 3 'te verilen değerler, Gri Sistemin $\operatorname{GM}(1, N)$ ve $\operatorname{GM}(1,1)$ tahmin modelleri ile elde edilmiştir. Tablonun ilk sütununda ölçü yapılan yıllar yer almaktadır. Tablonun ikinci sütununda ise su kotuna ait referans değeri olarak kullanılan değerler ile tahmin edilen değerler gösterilmiştir. Tablonun üçüncü sütununda piyezometrenin bulunduğu kot değeri, sonraki üç sütunda ise piyezometrenin tahmin edilen ölçü değerleri yer almaktadır. Tablonun son üç sütununda ise deformasyon durumu, kullanılan tahmin modelinin ürettiği tahmin değerlerine göre elde edilen sonuçların yorumlanmış halini gösterilmektedir.

Deformasyonun varlığında söz edebilmek için tahmin edilen değerlerin yer çekim katsayısına bölünmesi ile piyezometrenin bulunduğu yükseklik (Hücre uç kotu) değerinin toplanarak su kotu seviyesinden fazla olup olmadığına göre yorumlanmıştır. Su kotundan büyük olan tahmin değerlerinin bulunduğu yıllarda kritik değerlere yaklaşıldığının ve deformasyon olduğunun göstergesidir. 
Tablo 3. 5 Nolu piyezometre aletine ait tahmin değerleri ve deformasyon durumu.

\begin{tabular}{|c|c|c|c|c|c|c|c|c|}
\hline \multirow{2}{*}{ Yıllar } & \multicolumn{5}{|c|}{ P5 Nolu Piyezometre } & \multicolumn{3}{|c|}{ Deformasyon Tahmini } \\
\cline { 2 - 9 } & $\begin{array}{c}\text { Su Kotu } \\
\text { Değeri }\end{array}$ & $\begin{array}{c}\text { Hücre } \\
\text { Kotu }\end{array}$ & $\mathbf{G M}(\mathbf{1 , 2})$ & $\mathbf{G M}(\mathbf{1 , 3})$ & $\mathbf{G M}(\mathbf{1 , 4})$ & $\mathbf{G M}(\mathbf{1 , 2})$ & $\mathbf{G M}(\mathbf{1 , 3})$ & $\mathbf{G M ( 1 , 4 )}$ \\
\hline 2010 & $\mathbf{8 3 4 . 1 1 0}$ & 730.000 & 1350.000 & 1350.000 & 1350.000 & Var & Var & Var \\
\hline 2011 & $\mathbf{8 4 0 . 1 0 0}$ & 730.000 & 246.289 & 248.487 & 253.775 & Yok & Yok & Yok \\
\hline 2012 & $\mathbf{8 3 7 . 2 7 0}$ & 730.000 & 369.401 & 373.391 & 357.817 & Yok & Yok & Yok \\
\hline 2013 & $\mathbf{8 3 8 . 4 4 0}$ & 730.000 & 410.356 & 400.381 & 427.264 & Yok & Yok & Yok \\
\hline 2014 & $\mathbf{8 3 0 . 1 1 0}$ & 730.000 & 415.169 & 409.198 & 381.030 & Yok & Yok & Yok \\
\hline 2015 & $\mathbf{8 3 4 . 0 7 0}$ & 730.000 & 404.489 & 414.209 & 417.702 & Yok & Yok & Yok \\
\hline 2016 & 830.244 & 730.000 & 387.557 & 418.042 & 421.061 & Yok & Yok & Yok \\
\hline 2017 & 828.337 & 730.000 & 368.489 & 421.213 & 351.452 & Yok & Yok & Yok \\
\hline 2018 & 826.434 & 730.000 & 349.099 & 423.853 & 509.127 & Yok & Yok & Yok \\
\hline 2019 & 824.535 & 730.000 & 330.167 & 426.024 & 262.437 & Yok & Yok & Yok \\
\hline 2020 & 822.641 & 730.000 & 312.008 & 427.769 & 565.395 & Yok & Yok & Yok \\
\hline 2021 & 820.751 & 730.000 & 294.736 & 429.126 & 287.041 & Yok & Yok & Yok \\
\hline 2022 & 818.865 & 730.000 & 278.368 & 430.131 & 411.439 & Yok & Yok & Yok \\
\hline 2023 & 816.983 & 730.000 & 262.887 & 430.814 & 605.305 & Yok & Yok & Yok \\
\hline
\end{tabular}

Tablo 3'te yer alan deformasyon durumunu incelediğimizde, 2010 y1lına ait değerlerde deformasyonun olduğu görülmektedir. 2010 yılında barajın memba tarafindaki su kotu değeri, $834.11 \mathrm{~m}$ iken 5 numaralı piyezometre $1350 \mathrm{~kg} / \mathrm{cm}^{2}$ değeri okunmuştur. Bu değerin yer çekim sabitine bölünmesi ile 5 numaralı piyezometrenin bulunduğu sondaj kuyusundaki su seviyesinin 137.61 metreye karşllık geldiği hesaplanmıştır. Bu değerin piyezometrenin bulunduğu $730.00 \mathrm{~m}$ değerine eklenmesi ile 867.61 değeri bulunmuştur. Bu değer memba tarafindaki su kotundan büyük olduğundan deformasyon değerinin seviyeye ulaştı̆̆ını göstermektedir. Elde edilen diğer tahmin değerlerine göre barajda 2011 ve sonraki yıllarda deformasyon değerinin kritik seviyeye ulaşmayacağı tahmin edilmiştir.

Tablo 4'te 13 numaralı (P13) piyezometre aletine ait referans değerleri ve tahmin değerleri yer almaktadır. Tabloda altı adet ölçülen değer kullanılarak sonraki yıllara ait tahmin değerleri üretilmiştir. Gri Sistemin tek değişkenli ve çok değiş̧enli tahmin modelleri kullanılarak, 2010 yılından 2023 yılına kadar olan on bir yıllık tahmin değerleri oluşturulmuştur. $\mathrm{GM}(1,4)$ tahmin modeli kullanılarak elde edilen tahmin değerlerinin artan ve azalan şekilde değerler aldığı görülmüştür (Tablo 4). Bu durum referans verilerinde görülmemektedir. Bunun sebebinin, birlikte değerlendirilen su kotu ve diğer piyezometre aletlerinin referans ölçülerinin davranışları ile alakalı olduğu düşünülmektedir. Ancak benzer değişkenler diğer piyezometrelerin son sütununda yer alan ve GM $(1,4)$ tahmin modelinde elde edilen tahmin değerlerinde rastlanmamıştır.

Tablo 4. 13 Nolu piyezometre aletine ait tahmin değerleri.

\begin{tabular}{|c|c|c|c|c|c|}
\hline \multirow[b]{2}{*}{ Yillar } & \multicolumn{5}{|c|}{ P13 Nolu Piyezometre } \\
\hline & $\begin{array}{c}\text { Ölçülen Değer } \\
\left(\mathrm{kg} / \mathrm{cm}^{2}\right)\end{array}$ & $\begin{array}{c}\text { GM(1,1) } \\
(\text { P13) }\end{array}$ & $\begin{array}{l}\text { GM(1,2) } \\
\text { (P13-P19) }\end{array}$ & $\begin{array}{c}\text { GM(1,3) } \\
\text { (P13-P19-Su Kotu) }\end{array}$ & $\begin{array}{c}\text { GM(1,4) } \\
\text { (P13-P19-SuKotu-P5) }\end{array}$ \\
\hline 2010 & 280 & 280.000 & 280.000 & 280.000 & 280.000 \\
\hline 2011 & 386 & 368.048 & 378.130 & 378.190 & 355.007 \\
\hline 2012 & 284 & 317.666 & 306.350 & 307.151 & 369.633 \\
\hline 2013 & 304 & 274.180 & 262.542 & 261.326 & 155.549 \\
\hline 2014 & 200 & 236.648 & 235.661 & 234.035 & 343.609 \\
\hline 2015 & 230 & 204.253 & 219.022 & 219.998 & 229.567 \\
\hline 2016 & Tahmin Değeri & 176.293 & 208.582 & 215.167 & 161.779 \\
\hline 2017 & Tahmin Değeri & 152.160 & 201.894 & 216.526 & 517.527 \\
\hline 2018 & Tahmin Değeri & 131.331 & 197.478 & 221.891 & 195.593 \\
\hline 2019 & Tahmin Değeri & 113.353 & 194.439 & 229.729 & 852.534 \\
\hline 2020 & Tahmin Değeri & 97.836 & 192.234 & 238.998 & 356.308 \\
\hline 2021 & Tahmin Değeri & 84.444 & 190.536 & 249.021 & 646.540 \\
\hline 2022 & Tahmin Değeri & 72.884 & 189.147 & 259.382 & 405.161 \\
\hline 2023 & Tahmin Değeri & 62.907 & 187.946 & 269.844 & 773.631 \\
\hline \multicolumn{2}{|r|}{ Hata Oranı } & 0.754 & 0.875 & 0.793 & 7.484 \\
\hline
\end{tabular}


Tablo 5'te 13 numaralı piyezometre aletine ait deformasyon durumunu göstermektedir. 13 numaralı piyezometre aleti baraj kretinin 810.00 metresine yerleştirilmiştir. Gri sitemin tahmin modelleri yardımı ile elde edilen tahmin değerleri piyezometrenin yerleştirildiği hücre kotuna eklenerek deformasyon olup olmadiğ 1 yorumlanmıştır. 13 numaralı piyezometre aletinin su kotuna yakın bir seviyede olması ve gri tahmin modeli ile elde edilen tahmin değerlerinin büyük olması nedeniyle deformasyon değerinin kritik seviyede olduğu anlaşılmaktadır. Bu durumun referans alınan ölçü değerlerinde de aynı olduğu görülmüştür. Tahmin değerlerinin hata oranları dikkate alındığında $\operatorname{GM}(1,4)$ tahmin modelinin hata oranının diğer tahmin modellerine göre fazla olduğu görülmüştür.

Tablo 5. 13 Nolu piyezometre aletine ait tahmin değerleri ve deformasyon durumu.

\begin{tabular}{|c|c|c|c|c|c|c|c|c|}
\hline \multirow{2}{*}{ Yıllar } & \multicolumn{5}{|c|}{ P13 Nolu Piyezometre } & \multicolumn{3}{c|}{ Deformasyon Tahmini } \\
\cline { 2 - 9 } & $\begin{array}{c}\text { Su Kotu } \\
\text { Değeri }\end{array}$ & $\begin{array}{c}\text { Hücre } \\
\text { Kotu }\end{array}$ & GM(1,2) & GM(1,3) & GM(1,4) & GM(1,2) & GM(1,3) & GM(1,4) \\
\hline 2010 & $\mathbf{8 3 4 . 1 1 0}$ & 810.000 & 280.000 & 280.000 & 280.000 & Var & Var & Var \\
\hline 2011 & $\mathbf{8 4 0 . 1 0 0}$ & 810.000 & 378.130 & 378.190 & 355.007 & Var & Var & Var \\
\hline 2012 & $\mathbf{8 3 7 . 2 7 0}$ & 810.000 & 306.350 & 307.151 & 369.633 & Var & Var & Var \\
\hline 2013 & $\mathbf{8 3 8 . 4 4 0}$ & 810.000 & 262.542 & 261.326 & 155.549 & Yok & Yok & Yok \\
\hline 2014 & $\mathbf{8 3 0 . 1 1 0}$ & 810.000 & 235.661 & 234.035 & 343.609 & Var & Var & Var \\
\hline 2015 & $\mathbf{8 3 4 . 0 7 0}$ & 810.000 & 219.022 & 219.998 & 229.567 & Yok & Yok & Yok \\
\hline 2016 & 830.244 & 810.000 & 208.582 & 215.167 & 161.779 & Var & Var & Yok \\
\hline 2017 & 828.337 & 810.000 & 201.894 & 216.526 & 517.527 & Var & Var & Var \\
\hline 2018 & 826.434 & 810.000 & 197.478 & 221.891 & 195.593 & Var & Var & Var \\
\hline 2019 & 824.535 & 810.000 & 194.439 & 229.729 & 852.534 & Var & Var & Var \\
\hline 2020 & 822.641 & 810.000 & 192.234 & 238.998 & 356.308 & Var & Var & Var \\
\hline 2021 & 820.751 & 810.000 & 190.536 & 249.021 & 646.540 & Var & Var & Var \\
\hline 2022 & 818.865 & 810.000 & 189.147 & 259.382 & 405.161 & Var & Var & Var \\
\hline 2023 & 816.983 & 810.000 & 187.946 & 269.844 & 773.631 & Var & Var & Var \\
\hline
\end{tabular}

13 numaralı piyezometre aletine ait boşluk suyu basınç miktarı ve deformasyon durumu incelendiğinde birçok yılda deformasyonun olduğu veya deformasyonun kritik seviyeye yaklaştığı ve hatta kritik seviyeyi geçtiği görülmektedir (Tablo 5).

Tablo 6. 19 Nolu piyezometre aletine ait ölçü ve tahmin değerleri.

\begin{tabular}{|c|c|c|c|c|c|}
\hline \multirow{2}{*}{ Yıllar } & \multicolumn{5}{|c|}{ P19 Nolu Piyezometre } \\
\hline & $\begin{array}{c}\text { Ölçülen Değer } \\
\left(\mathrm{kg} / \mathrm{cm}^{2}\right)\end{array}$ & $\begin{array}{c}\text { GM(1,1) } \\
(\mathbf{P 1 9}) \\
\end{array}$ & $\begin{array}{c}\text { GM(1,2) } \\
\text { (P19-Su Kotu) }\end{array}$ & $\begin{array}{c}\text { GM(1,3) } \\
\text { (P19-Su Kotu-P5) } \\
\end{array}$ & $\begin{array}{c}\text { GM(1,4) } \\
\text { (P19-Su Kotu-P5-P13) }\end{array}$ \\
\hline 2010 & 820 & 820.000 & 820.000 & 820.000 & 820.000 \\
\hline 2011 & 822 & 825.611 & 822.813 & 822.934 & 822.389 \\
\hline 2012 & 830 & 827.202 & 829.551 & 829.556 & 831.319 \\
\hline 2013 & 832 & 828.797 & 831.232 & 831.000 & 828.605 \\
\hline 2014 & 830 & 830.394 & 830.907 & 830.837 & 831.747 \\
\hline 2015 & 830 & 831.995 & 829.787 & 829.929 & 832.287 \\
\hline 2016 & Tahmin Değeri & 833.599 & 828.354 & 828.622 & 827.222 \\
\hline 2017 & Tahmin Değeri & 835.206 & 826.799 & 827.097 & 839.528 \\
\hline 2018 & Tahmin Değeri & 836.816 & 825.196 & 825.450 & 820.951 \\
\hline 2019 & Tahmin Değeri & 838.429 & 823.577 & 823.738 & 844.327 \\
\hline 2020 & Tahmin Değeri & 840.045 & 821.953 & 821.991 & 823.366 \\
\hline 2021 & Tahmin Değeri & 841.665 & 820.329 & 820.226 & 833.069 \\
\hline 2022 & Tahmin Değeri & 843.287 & 818.708 & 818.452 & 848.198 \\
\hline 2023 & Tahmin Değeri & 844.913 & 817.089 & 816.676 & 797.352 \\
\hline \multicolumn{2}{|c|}{ Hata Oranı } & 0.001 & 0.006 & 0.005 & 0.047 \\
\hline
\end{tabular}

Tablo 6'da yer alan 19 numaralı piyezometreye ait tahmin değerleri ve tahmin değerlerine ait hata oranları incelendiğinde başarılı tahmin değerlerinin üretildiği görülmektedir. 19 numaralı piyezometrenin ölçtüğ̈ boşluk suyu basınç değerine göre herhangi bir yılda meydana gelebilecek bir deformasyon beklentisi bulunmamaktadır.

Deformasyon tahmininde kullanılmak üzere ölçülen tahmin değerleri beklenildiği gibi çıkmıştır. Bunun yanı sıra ölçülen altı yıllık su kotuna ait veriler yılllık yağı̧̧ ve kuraklığa bağlı olarak dalgalı bir artış azalış göstermektedir. 2015 yılından sonraki yıllarda tahmin edilen su kotu seviyesi Gri Sistemin tek değişkenli tahmin 
modeli olan $\mathrm{GM}(1,1)$ 'in karekteristik özelliği gereği doğrusal olarak azalmaktadır. Su kotuna ait bu tahmin değerleri mevcut gerçek durumdan farklılık göstermektedir. 19 numaralı piyezometreye ait ölçülen ve tahmin edilen değerler ile su kotu seviyesine ait ölçülen ve tahmin edilen değerler Tablo 7'de verilmiş̧ir. Tablo 7' de yer alan değerlere göre barajda herhangi bir yıl için deformasyonun olmayacağı tahmin edilmiştir.

Tablo 7. 19 Nolu piyezometre aletine ait tahmin değerleri ve deformasyon durumu.

\begin{tabular}{|c|c|c|c|c|c|c|c|c|}
\hline \multirow{2}{*}{ Yıllar } & \multicolumn{7}{|c|}{ P19 Nolu Piyezometre } & \multicolumn{3}{c|}{ Deformasyon Tahmini } \\
\cline { 2 - 9 } & $\begin{array}{c}\text { Su Kotu } \\
\text { Değeri }\end{array}$ & $\begin{array}{c}\text { Hücre } \\
\text { Kotu }\end{array}$ & $\mathbf{G M}(\mathbf{1 , 2})$ & $\mathbf{G M ( 1 , 3 )}$ & $\mathbf{G M ( 1 , 4 )}$ & GM(1,2) & GM(1,3) & GM(1,4) \\
\hline 2010 & $\mathbf{8 3 4 . 1 1 0}$ & 720.000 & 820.000 & 820.000 & 820.000 & Yok & Yok & Yok \\
\hline 2011 & $\mathbf{8 4 0 . 1 0 0}$ & 720.000 & 822.813 & 822.934 & 822.389 & Yok & Yok & Yok \\
\hline 2012 & $\mathbf{8 3 7 . 2 7 0}$ & 720.000 & 829.551 & 829.556 & 831.319 & Yok & Yok & Yok \\
\hline 2013 & $\mathbf{8 3 8 . 4 4 0}$ & 720.000 & 831.232 & 831.000 & 828.605 & Yok & Yok & Yok \\
\hline 2014 & $\mathbf{8 3 0 . 1 1 0}$ & 720.000 & 830.907 & 830.837 & 831.747 & Yok & Yok & Yok \\
\hline 2015 & $\mathbf{8 3 4 . 0 7 0}$ & 720.000 & 829.787 & 829.929 & 832.287 & Yok & Yok & Yok \\
\hline 2016 & 830.244 & 720.000 & 828.354 & 828.622 & 827.222 & Yok & Yok & Yok \\
\hline 2017 & 828.337 & 720.000 & 826.799 & 827.097 & 839.528 & Yok & Yok & Yok \\
\hline 2018 & 826.434 & 720.000 & 825.196 & 825.450 & 820.951 & Yok & Yok & Yok \\
\hline 2019 & 824.535 & 720.000 & 823.577 & 823.738 & 844.327 & Yok & Yok & Yok \\
\hline 2020 & 822.641 & 720.000 & 821.953 & 821.991 & 823.366 & Yok & Yok & Yok \\
\hline 2021 & 820.751 & 720.000 & 820.329 & 820.226 & 833.069 & Yok & Yok & Yok \\
\hline 2022 & 818.865 & 720.000 & 818.708 & 818.452 & 848.198 & Yok & Yok & Yok \\
\hline 2023 & 816.983 & 720.000 & 817.089 & 816.676 & 797.352 & Yok & Yok & Yok \\
\hline
\end{tabular}

\section{Sonuçlar}

Bu çalışmada, Keban Barajı'nın toprak dolgu kısmında yer alan piyezometrelere ait boşluk suyu basınç değerleri ve bu basınç değerleri ile yakından ilişkili olan baraj su kotu miktarı Gri Sistem ile tahmin edilmiştir. Keban Baraj göletindeki su seviyesi değerleri, Gri tahmin yöntem ile yeniden değerlendirilmiştir. Aynı şekilde baraj kretinde yer alan ve krette oluşan boşluk suyu basıncı miktarını tespit etmek için yerleştirilen piyezometre aletlerine ait değerleri de yine gri tahmin yönteminin $\operatorname{GM}(1, N)$ model yöntemi ile değerlendirilmiş̧ir. Yapılan değerlendirme sonuçlarına göre elde edilen tahmin verileri gerçek anlamda barajda oluşan deformasyon değerlerini temsil etmemekle birlikte, oluşabilecek deformasyon miktarları hakkında anlamlı bilgi vermektedir. Elde edilen tahmin değerleri, Gri Sistem'in deformasyon analizinde kullanılabilir bir yöntem olduğunu göstermiştir.

\section{Bilgi}

Bu çalışma, Fırat Üniversitesi, Fen Bilimleri Enstitüsü, Kürşat Kaya (2019), Deformasyon Tahmininde Gri Model Uygulaması: Keban Barajı Örneği, Yüksek Lisans Tezinden üretilmiştir.

\section{Kaynaklar}

[1] Kaya, K., "Deformasyon Tahmininde Gri Model Uygulaması: Keban Barajı Örneği”, Yüksek Lisans Bitirme Tezi, Fırat Üniversitesi Fen Bilimleri Enstitüsü, 2019.

[2] Deng, J. L., Grey forecasting and decision, Huazhong University of Science and Technology Press. 1986.

[3] Hoşbaş, R. G., "Baraj Deformasyonlarının Belirlenmesinde Jeodezik Yaklaşımların İrdelenmesi ve Bir Öneri”, Doktora Tezi, YTÜ Fen Bilimleri Enstitüsü, İstanbul, 1992.

[4] Kalkan Y. ve Alkan R. M., "Mühendislik Yapılarında Deformasyon Ölçmeleri” Harita ve Kadastro Mühendisleri Odası, Mühendislik Ölçmeleri STB Komisyonu 2. Mühendislik Ölçmeleri Sempozyumu 23-25 Kasım 2005, İTÜ - İstanbul.

[5] Yalçınkaya M. ve Kayıkçı E. T., "Dengeleme Heabı-II Ders Norları" Karadeniz Teknik Üniversitesi, Harita Mühendisliği Bölümü, Trabzon, 2019.

[6] Liu, S. ve Lin, Y., “Grey Information: Theory and Practical Applications”, Springer, 11-21. 2006.

[7] Liu, S. F. ve Lin, Y., An Introduction to Grey Systems Theory. Grove City: IIGSS Academic Publisher, 1998.

[8] Lin, C.T. ve Yang, S.Y., "Forecast of the output value of Taiwan's IC Industry Using the Grey Forecasting Model", International Journal Computer Applications in Technology, 19: 23-27., 2004.

[9] Özgen, N., "Keban Barajı ve Tarihçesi” DS_Vakfi yayın No:1 Ankara. 2000.

[10] URL-4, 15:28, 21.02.219, http://www.dsi.gov.tr/projeler/keban-baraj1. 